\title{
Vancomycin and High Level Aminoglycoside Resistance in Enterococcus spp. in a Tertiary Health Care Centre: A Therapeutic Concern
}

\author{
Seema Mittal, ${ }^{1}$ Pooja Singla, ${ }^{2}$ Antariksha Deep, ${ }^{3}$ Kiran Bala, ${ }^{3}$ Rama Sikka, \\ Meenu Garg, ${ }^{3}$ and Uma Chaudhary ${ }^{3}$ \\ ${ }^{1}$ BPS GMC (Women), Khanpur Kalan, Sonepat, Haryana, India \\ ${ }^{2}$ SHKMC, Mewat, Haryana, India \\ ${ }^{3}$ PGIMS, Rohtak, Haryana, India \\ Correspondence should be addressed to Seema Mittal; simamicro@gmail.com
}

Received 11 October 2015; Revised 10 February 2016; Accepted 15 February 2016

Academic Editor: Nongnuch Vanittanakom

Copyright (C) 2016 Seema Mittal et al. This is an open access article distributed under the Creative Commons Attribution License, which permits unrestricted use, distribution, and reproduction in any medium, provided the original work is properly cited.

Aims. This study was aimed at knowing the prevalence of vancomycin and high level aminoglycoside resistance in enterococcal strains among clinical samples. Study Design. It was an investigational study. Place and Duration of Study. It was conducted on 100 Enterococcus isolates, in the Department of Microbiology, Pt. BDS PGIMS, Rohtak, over a period of six months from July to December 2014. Methodology. Clinical specimens including urine, pus, blood, semen, vaginal swab, and throat swab were processed and Enterococcus isolates were identified by standard protocols. Antibiotic sensitivity testing of enterococci was performed using Kirby-Bauer disc diffusion method. Results. High level gentamicin resistance (HLGR) was more common in urine samples (41.5\%) followed by blood (36\%) samples. High level streptomycin resistance (HLSR) was more common in pus samples (52.6\%) followed by blood samples (36\%). Resistance to vancomycin was maximum in blood isolates. Conclusion. Enterococci resistant to multiple antimicrobial agents have been recognized. Thus, it is crucial for laboratories to provide accurate antimicrobial resistance patterns for enterococci so that effective therapy and infection control measures can be initiated.

\section{Introduction}

Enterococcus has emerged as a nosocomial pathogen in the last two decades, causing urinary tract infections, genital tract infections, and endocarditis due to its colonizing capacity and multidrug resistance $[1,2]$. The emergence of multidrug resistant enterococci to commonly used antibiotics, for example, aminoglycosides and cephalosporins, is because of their ability to attain and transfer the drug resistance gene, giving rise to enterococci with high level aminoglycoside (HLAR) and glycopeptide resistance [3]. They are less susceptible to penicillins and aminoglycoside antibiotics. However, combinations of penicillins with aminoglycosides are synergistically bactericidal against enterococci in vitro and are effective in treating severe enterococcal endocarditis. The mechanism of this synergy has been explained by the enhanced uptake of aminoglycosides in the presence of penicillins or other agents which inhibit cell wall synthesis [4]. An increased frequency of high level resistance to aminoglycoside antibiotics (MIC $>8,000 \mu \mathrm{g} / \mathrm{mL}$ ) in clinical isolates of enterococci has been reported which were also resistant to synergism with the penicillins [5].

This study was aimed at determining the antibiotic susceptibility of enterococci isolated from various clinical samples with reference to aminoglycoside and vancomycin. So if the knowledge of HLAR prevalence is available, clinicians can prescribe the various drug combination (cell wall inhibitor + aminoglycosides) at the very beginning of treatment avoiding the unnecessary usage of other antimicrobials.

\section{Material and Methods}

This study was conducted on 100 isolates of Enterococcus spp. from various clinical specimens including urine, pus, 
TABLE 1: Antibiotic resistance pattern of Enterococcus spp. in clinical specimen by disc diffusion test.

\begin{tabular}{|c|c|c|c|c|c|}
\hline & Urine/semen, $n=41(\%)$ & Pus, $n=19(\%)$ & Blood, $n=25(\%)$ & High vaginal swab, $n=7(\%)$ & Drain, $n=8(\%)$ \\
\hline Nitrofurantoin & $10(24.4 \%)$ & - & - & - & - \\
\hline Linezolid & 0 & 0 & 0 & 0 & $1(12.5 \%)$ \\
\hline Vancomycin & $1(2.4 \%)$ & 0 & $4(16.25 \%)$ & 0 & 0 \\
\hline Penicillin & - & - & $16(64 \%)$ & - & $4(50 \%)$ \\
\hline Erythromycin & $20(49 \%)$ & $8(42 \%)$ & $1(4 \%)$ & 0 & $1(12.5 \%)$ \\
\hline Doxycycline & $12(29 \%)$ & 0 & 0 & 0 & 0 \\
\hline Ciprofloxacin & $22(53.6 \%)$ & $3(15.7 \%)$ & 0 & 0 & 0 \\
\hline
\end{tabular}

TABle 2: Prevalence of High level resistance in Enterococcus spp. isolates.

\begin{tabular}{|c|c|c|c|c|c|}
\hline Antibiotic & $\begin{array}{c}\mathrm{U} / \mathrm{S} \\
n=41(\%)\end{array}$ & Pus, $n=19(\%)$ & Blood, $n=25(\%)$ & HVS, $n=7(\%)$ & Drain, $n=8(\%)$ \\
\hline Gentamicin $(120 \mu \mathrm{g})$ & $17(41.5 \%)$ & $3(16 \%)$ & $9(36 \%)$ & 0 & 0 \\
\hline Streptomycin $(300 \mu \mathrm{g})$ & $14(34 \%)$ & $10(52.6 \%)$ & $9(36 \%)$ & $1(14 \%)$ & $1(12.5 \%)$ \\
\hline
\end{tabular}

U/S: urine/semen; HVS: high vaginal swab.

blood, semen, vaginal swab, and throat swab during a period of six months from July to December 2014. The samples were processed immediately after collection and Enterococcus isolates were identified by standard protocols based on Gram's staining, colony morphology, catalase test, bile solubility, growth in sodium chloride, bile esculin test, and sugar fermentation tests [6].

Antibiotic sensitivity testing of enterococci was performed using Kirby-Bauer disc diffusion method and Mueller-Hinton agar supplemented with $5 \%$ sheep blood was used as per CLSI guidelines [7]. The antibiotics discs used were penicillin $(10 \mathrm{U})$, gentamicin $(10 \mu \mathrm{g})$, ciprofloxacin $(5 \mu \mathrm{g})$, linezolid $(30 \mu \mathrm{g})$, vancomycin $(30 \mu \mathrm{g})$, erythromycin $(15 \mu \mathrm{g})$, and doxycycline $(30 \mu \mathrm{g})$, and nitrofurantoin $(300 \mu \mathrm{g})$ was also added in urinary isolates.

HLAR in enterococci was detected by disc diffusion method. In disc diffusion method, high level $(120 \mu \mathrm{g})$ gentamicin and streptomycin $(300 \mu \mathrm{g})$ discs were placed on the agar medium. Plates were incubated at $37^{\circ} \mathrm{C}$ for 24 hours, and diameter of zone of inhibition was measured. Resistance was indicated by no zone and susceptibility by a zone of diameter $\geq 10 \mathrm{~mm}$. The test was quality controlled using $E$. faecalis ATCC 29212 (susceptible) and E. faecalis ATCC 51299 (resistant) [8].

Vancomycin resistance was determined by using E-strip (Hi-media) on blood agar for those isolates which were resistant by disc diffusion test.

\section{Results}

Out of a total of 100 isolates, $41 \%$ from urine and semen and $25 \%$ from blood followed by $19 \%$ from pus and $8 \%$ from body fluid drains were included in the study. The majority of clinical samples from which Enterococcus spp. were recovered were from indoor $(60 \%)$ in comparison to outdoor $(40 \%)$ patients.

Enterococcus isolates from blood samples were resistant to penicillin $(64 \%)$, and urinary isolates were resistant to fluoroquinolones (53.6\%). Commonly used antimicrobials were found to be sensitive in Enterococcus spp. recovered from vaginal swab samples (Table 1).

High level gentamicin resistance (HLGR) was more common in urine samples $(41.5 \%)$ followed by blood $(36 \%)$ samples. High level streptomycin resistance (HLSR) was more common in pus samples $(52.6 \%)$ followed by blood samples (36\%) (Table 2).

In Table 3, more resistance to nitrofurantoin in Enterococcus isolates from urine samples was not noticed in indoor (17\%) patients in comparison to OPD (7.3\%). Similarly resistant to glycopeptides (vancomycin), fluoroquinolones were more common in hospitalized patients. Also, HLAR was more common in indoor (39\%) versus outdoor patients (25\%) (Table 3).

Resistance to vancomycin was maximum in blood isolates, that is, $32 \%$. It was more common in IPD patients $(28 \%)$ as compared to OPD patients (4\%). High level aminoglycoside resistance was more common in vancomycin resistant enterococci (VRE) isolates than vancomycin sensitive enterococci (VSE) isolates. Five out of nine of the Enterococcus isolates resistant to vancomycin by disk diffusion test were found resistant to these glycopeptides by E-strip test (Table 4).

\section{Discussion}

Over the last few years, they have become important nosocomial pathogens probably due to inherent resistance to antibiotics (cephalosporins), ability to adhere to indwelling medical devices, and ability to survive in adverse environmental conditions. Antimicrobial resistance in Enterococcus has been increasing mainly in hospitalized patients [9-11].

In our study, out of the total 100 Enterococcus isolates from different clinical specimens, the majority were recovered from hospitalized $(60 \%)$ patients in comparison to outdoor (40\%) patients, similar to other studies [12].

A combination of penicillin and aminoglycosides is considered as treatment of choice for enterococcal infections; 
TABLE 3: Prevalence of antibiotic resistance in Enterococcus spp. in various clinical samples in IPD/OPD settings.

\begin{tabular}{|c|c|c|c|c|c|c|c|c|c|c|}
\hline & \multicolumn{2}{|c|}{$\mathrm{U} / \mathrm{S}, n=41$} & \multicolumn{2}{|c|}{ Pus, $n=19$} & \multicolumn{2}{|c|}{ Blood, $n=25$} & \multicolumn{2}{|c|}{ HVS, $n=7$} & \multicolumn{2}{|c|}{ Drain, $n=8$} \\
\hline & IPD & OPD & IPD & OPD & IPD & OPD & IPD & OPD & IPD & OPD \\
\hline Nitrofurantoin & $7(17 \%)$ & $3(7.3 \%)$ & - & - & - & - & - & - & - & - \\
\hline Linezolid & 0 & 0 & 0 & 0 & - & - & 0 & 0 & $1(12.5 \%)$ & 0 \\
\hline Vancomycin & $1(2.4 \%)$ & 0 & 0 & 0 & $3(12 \%)$ & $1(4 \%)$ & 0 & 0 & 0 & 0 \\
\hline Penicillin & - & - & - & - & $12(48 \%)$ & $4(16 \%)$ & - & - & $4(50 \%)$ & 0 \\
\hline Erythromycin & & & $6(31.5 \%)$ & $2(10.5 \%)$ & $1(4 \%)$ & 0 & 0 & 0 & $1(12.5 \%)$ & 0 \\
\hline Doxycycline & $5(12 \%)$ & $7(17 \%)$ & 0 & 0 & 0 & 0 & 0 & 0 & 0 & 0 \\
\hline Ciprofloxacin & $12(29 \%)$ & $10(24 \%)$ & $3(15.7 \%)$ & 0 & 0 & 0 & 0 & 0 & 0 & 0 \\
\hline HLG & $7(17 \%)$ & $10(24 \%)$ & $3(15.7 \%)$ & 0 & $7(28 \%)$ & $2(8 \%)$ & 0 & 0 & 0 & 0 \\
\hline HLS & $5(12 \%)$ & $9(22 \%)$ & $9(47 \%)$ & $1(5 \%)$ & $7(28 \%)$ & $2(8 \%)$ & 0 & $1(14.3 \%)$ & $1(1.25 \%)$ & 0 \\
\hline
\end{tabular}

U/S: urine semen; HVS: high vaginal swab.

therefore, resistance against these antibiotics has important clinical results effecting therapeutic prognosis. In the present study, Enterococcus isolates from blood samples were found to be penicillin resistant in $64 \%$ strains $(16 / 25=64 \%)($ MIC ranges from 16 to $32 \mu \mathrm{g} / \mathrm{mL}$ ), which could be due to resistance mechanism involving low affinity penicillin binding proteins or production of $\beta$ lactamases.

In this study, prevalence of drug resistance to various antibiotics was as follows: ciprofloxacin (25\%), penicillin (66.67\%), and nitrofurantoin in urinary isolates (24.3\%). Linezolid and vancomycin were found sensitive in $99 \%$ and 95\% isolates of enterococcus. One isolate of Enterococcus spp. was found to be resistant to linezolid having inhibitory zone of diameter less than $15 \mathrm{~mm}$. This type of antibiogram has been documented in earlier studies also [12-14].

Here a low prevalence of fluoroquinolone (25\%) and other antibiotic resistance was found in comparison to other studies, $72 \%$ [12] and 62\% [13], respectively, which could be due to very precise and judicious use of this antimicrobial in our institute.

The present study demonstrated high prevalence of HLAR (gentamicin and streptomycin) $29 \%$ and 35\%, respectively. HLGR was more common in urine samples (41.5\%) followed by blood (36\%) samples. These findings are also reported in some studies [15]. However, a higher and lower prevalence level of HLGR and HLSR have been reported in few studies, respectively $[13,14,16]$.

In our study, HLAR to both gentamicin and streptomycin was found in $22 \%$ isolates, specifically more in blood isolates. Some studies reported higher prevalence of HLAR to both gentamicin and streptomycin [16].

HLAR in these enterococcal strains nullify the efficacy of beta lactam and aminoglycoside combination therapy. Therefore, differentiation of HLAR from simple intrinsic resistance is important and should be adopted as a part of routine microbiology laboratories.

In this study, it was found that HLAR was more common in IPD (28\%) as compared to OPD patients (4\%), similar to other studies [12].

Vancomycin resistance was found in nine isolates of Enterococcus by disc diffusion method; out of nine isolates five
TABle 4: Pattern of vancomycin susceptibility in Enterococcus spp. in various clinical specimens.

\begin{tabular}{lcc}
\hline Clinical specimen & $\begin{array}{c}\text { Vancomycin } \\
\text { susceptible } n(\%)\end{array}$ & $\begin{array}{c}\text { Vancomycin } \\
\text { resistant } n(\%)\end{array}$ \\
\hline Urine/semen & 40 & 1 \\
Pus & 19 & 0 \\
Blood & 21 & 4 \\
High vaginal swab & 7 & 0 \\
Drain fluid & 8 & 0 \\
Total & 95 & 5 \\
\hline
\end{tabular}

TABle 5: Prevalence of HLAR in VRE.

\begin{tabular}{lccc}
\hline VRE in clinical samples & HLGR & HLSR & HLGR + HLSR \\
\hline Urine $(n=1)$ & $1(100 \%)$ & 0 & 0 \\
Blood $(n=4)$ & $3(75 \%)$ & $3(75 \%)$ & $3(75 \%)$ \\
\hline
\end{tabular}

isolates were confirmed as VRE on E-strip test having MIC $(>64 \mu \mathrm{gm} / \mathrm{mL})$.

In India, the prevalence of VRE has been reported to be between 0 and 30 per cent [17-22]. In the present study, resistance to vancomycin was maximum in blood isolates, that is, $16.25 \%(4 / 25)$, with more prevalence in indoor patients (Table 4). It could be explained by the facts that in hospitalized patients use of broad spectrum antimicrobials is common practice and it leads to colonization pressure for selection of vancomycin resistance strains [23]. It may increase the risk of cross-infection among hospitalized patients via staff members and environmental contamination with VRE strains.

Out of four VRE strains, three were found to be sensitive to higher concentration of either of or both the aminoglycosides (Table 5). So the combination of the higher level aminoglycoside with cell wall inhibitor can be considered for treatment of VRE infection after antibiotic susceptibility testing.

Control Efforts. Due to lack of effective therapy for multiple antibiotic resistant enterococcal infection, prevention of 
the dissemination of these strains is of paramount significance. A very precise use of antimicrobials, for example, cephalosporins [24], and anti aerobic drugs [25] should be in practice. There are certain recommendations to reduce the cross-contamination by these organisms which include surveillance for colonization, identification of colonized and infected patients with their isolation, the use of gowns and gloves by health staff (barrier method), hand washing with an antiseptic after gloves removal, and avoiding contact with environmental surfaces after gloves removal. Medical equipment, for example, stethoscopes and blood pressure cuffs, must be dedicated to HLR patients. Environmental decontamination is also required with effective disinfectants (isopropyl alcohol, hypochlorite, and phenolic and quaternary ammonium salts) [26-29].

\section{Conclusion}

Deficiency of effective antimicrobial therapy and control measure for prevention of dissemination for multiple drug resistant enterococci are among the major factors for increasing prevalence of VRE and HLAR. Such strains pose therapeutic failure for clinicians. Thus, it becomes important for laboratories to provide accurate antimicrobial resistance patterns for enterococci so that effective therapy and infection control measures can be initiated. It becomes equivalently important that clinicians who are in direct contact with patients should go primarily for first/low generation of antibiotics for simple infections, for example, sore throat, rather than switching to higher class of antimicrobials.

\section{Conflict of Interests}

There is no conflict of interests.

\section{References}

[1] R. R. Facklam and L. M. Teixeira, "Enterococcus," in Topley \& Wilson's Microbiology and Microbial Infections, L. Collier, A. Balows, and M. Sussman, Eds., pp. 669-682, Arnold, London, UK, 1998.

[2] M. J. Zervos, C. A. Kauffman, P. M. Therasse, A. G. Bergman, T. S. Mikesell, and D. R. Schaberg, "Nosocomial infection by gentamicin-resistant, Streptococcus faecalis. An epidemiologic study," Annals of Internal Medicine, vol. 106, no. 5, pp. 687-691, 1987.

[3] M. A. Schouten, J. A. A. Hoogkamp-Korstanje, J. F. G. Meis, and A. Voss, "Prevalence of vancomycin-resistant enterococci in Europe," European Journal of Clinical Microbiology and Infectious Diseases, vol. 19, no. 11, pp. 816-822, 2000.

[4] R. A. Zimmermann, R. C. Moellering Jr., and A. N. Weinberg, "Mechanism of resistance to antibiotic synergism in enterococci," Journal of Bacteriology, vol. 105, no. 3, pp. 873-879, 1971.

[5] R. C. Moellering Jr., C. Wennersten, T. Medrek, and A. N. Weinberg, "Prevalence of high-level resistance to aminoglycosides in clinical isolates of enterococci," Antimicrobial Agents and Chemotherapy, vol. 10, pp. 335-340, 1970.

[6] J. G. Collee, J. P. Duguid, A. G. Fraser, B. P. Marmion, and A. Simmons, "Laboratory strategy in the diagnosis of infective syndromes," in Mackie and McCartney Practical Medical Microbiology, J. G. Collee, J. P. Duguid, A. G. Fraser, B. P. Marmion, and A. Simmons, Eds., pp. 84-90, Churchill Livingstone, New York, NY, USA, 14th edition, 1996.

[7] J. H. Jorgensen and J. D. Turnidge, "Susceptibility test methods: dilution and disk diffusion method," in Manual of Clinical Microbiology, P. R. Murray, E. J. Baron, J. H. Jorgensen, M. A. Pfaller, and R. H. Yolken, Eds., pp. 1108-1127, ASM Press, Washington, DC, USA, 2003.

[8] J. M. Swenson, J. F. Hindler, and J. H. Jorgensen, "Special phenotypic methods for detecting antibacterial resistance," in Manual of Clinical Microbiology, P. R. Murray, E. J. Baron, J. H. Jorgensen, M. A. Pfaller, and R. H. Yolken, Eds., pp. 1178-1195, ASM Press, Washington, DC, USA, 2003.

[9] E. E. Udo, N. Al-Sweih, O. A. Phillips, and T. D. Chugh, "Species prevalence and antibacterial resistance of enterococci isolated in Kuwait hospitals," Journal of Medical Microbiology, vol. 52, no. 2, pp. 163-168, 2003.

[10] J. Blahová, K. Králiková, V. Krćméry et al., "Monitoring of antibiotic resistance in bacterial isolates from bacteremic patients," Journal of Chemotherapy, vol. 16, no. 3, pp. 269-272, 2004.

[11] M. E. Jones, D. C. Draghi, C. Thornsberry, J. A. Karlowsky, D. F. Sahm, and R. P. Wenzel, "Emerging resistance among bacterial pathogens in the intensive care unit-a European and North American surveillance study (2000-2002)," Annals of Clinical Microbiology and Antimicrobials, vol. 3, article 14, 2004.

[12] S. Jain, A. Kumar, B. Kashyap, and I. Kaur, "Clinico-epidemiological profile and high-level aminoglycoside resistance in enterococcal septicemia from a tertiary care hospital in east Delhi," International Journal of Applied and Basic Medical Research, vol. 1, no. 2, pp. 80-83, 2011.

[13] L. Shah, S. Mulla, K. G. Patel, and S. Rewadiwala, "Prevalence of Enterococci with higher resistance level in a tertiary care hospital: a matter of concern," National Journal of Medical Research, vol. 2, pp. 25-27, 2012.

[14] K. Suresh, B. Saipriya, and G. Viswanath, "Isolation speciation and determination of high level aminoglycoside resistance of enterococci among hospitalised patients in davangere," National Journal of Laboratory Medicine, vol. 2, no. 1, pp. 12-15, 2013.

[15] K. G. Bhat, C. Paul, and M. G. Bhat, "Neonatal bacteremia due to high level aminoglycoside resistant (HLAR) Enterococci," Indian Journal of Pediatrics, vol. 64, no. 4, pp. 537-539, 1997.

[16] S. C. Fernandes and B. Dhanashree, "Drug resistance \& virulence determinants in clinical isolates of Enterococcus species," Indian Journal of Medical Research, vol. 137, no. 5, pp. 981-985, 2013.

[17] L. Kapoor, V. S. Randhawa, and M. Deb, "Antimicrobial resistance 17. Of enterococcal blood isolates at a pediatric care hospital in India," Japanese Journal of Infectious Diseases, vol. 58, no. 2, pp. 101-103, 2005.

[18] J. Agarwal, R. Kalyan, and M. Singh, "High-level aminoglycoside resistance and $\beta$-lactamase production in enterococci at a tertiary care hospital in India," Japanese Journal of Infectious Diseases, vol. 62, no. 2, pp. 158-159, 2009.

[19] P. Mathur, A. Kapil, R. Chandra, P. Sharma, and B. Das, "Antimicrobial resistance in Enterococcus faecalis at a tertiary care centre of northern India," Indian Journal of Medical Research, vol. 118, pp. 25-28, 2003.

[20] M. G. Karmarkar, E. S. Gershom, and P. R. Mehta, "Enterococcal infections with special reference to phenotypic characterization 
\& drug resistance," Indian Journal of Medical Research, Supplement, vol. 119, supplement, pp. 22-25, 2004.

[21] V. S. Randhawa, L. Kapoor, V. Singh, and G. Mehta, "Aminoglycoside 22. resistance in enterococci isolated from paediatric septicaemia in a tertiary care hospital in north India," Indian Journal of Medical Research, vol. 119, supplement, pp. 77-79, 2004.

[22] N. Taneja, P. Rani, R. Emmanuel, and M. Sharma, "Significance of vancomycin resistant enterococci from urinary specimens at a tertiary care centre in northern India," Indian Journal of Medical Research, vol. 119, pp. 72-74, 2004.

[23] M. J. M. Bonten, S. Slaughter, A. W. Ambergen et al., “The role of 'colonization pressure' in the spread of vancomycin-resistant enterococci: an important infection control variable," Archives of Internal Medicine, vol. 158, no. 10, pp. 1127-1132, 1998.

[24] C. J. Donskey, T. K. Chowdhry, M. T. Hecker et al., "Effect of antibiotic therapy on the density of vancomycin-resistant enterococci in the stool of colonized patients," The New England Journal of Medicine, vol. 343, no. 26, pp. 1925-1932, 2000.

[25] S. J. Bradley, A. L. T. Wilson, M. C. Allen, H. A. Sher, A. H. Goldstone, and G. M. Scott, "The control of hyperendemic glycopeptide-resistant Enterococcus spp. on a haematology unit by changing antibiotic usage," Journal of Antimicrobial Chemotherapy, vol. 43, no. 2, pp. 261-266, 1999.

[26] B. E. Murray, "Vancomycin-resistant enterococcal infections," The New England Journal of Medicine, vol. 342, no. 10, pp. 710721, 2000.

[27] B. E. Murray, "Vancomycin-resistant enterococci," The American Journal of Medicine, vol. 102, no. 3, pp. 284-293, 1997.

[28] L. B. Rice, "Emergence of vancomycin-resistant enterococci," Emerging Infectious Diseases, vol. 7, no. 2, pp. 183-187, 2001.

[29] S. DeLisle and T. M. Perl, "Vancomycin-resistant enterococci: a road map on how to prevent the emergence and transmission of antimicrobial resistance," Chest, vol. 123, no. 5, pp. 504S-518S, 2003. 


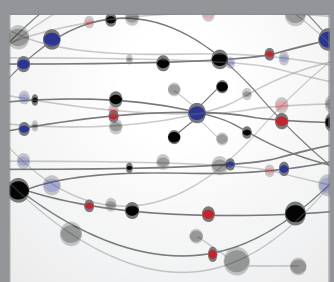

The Scientific World Journal
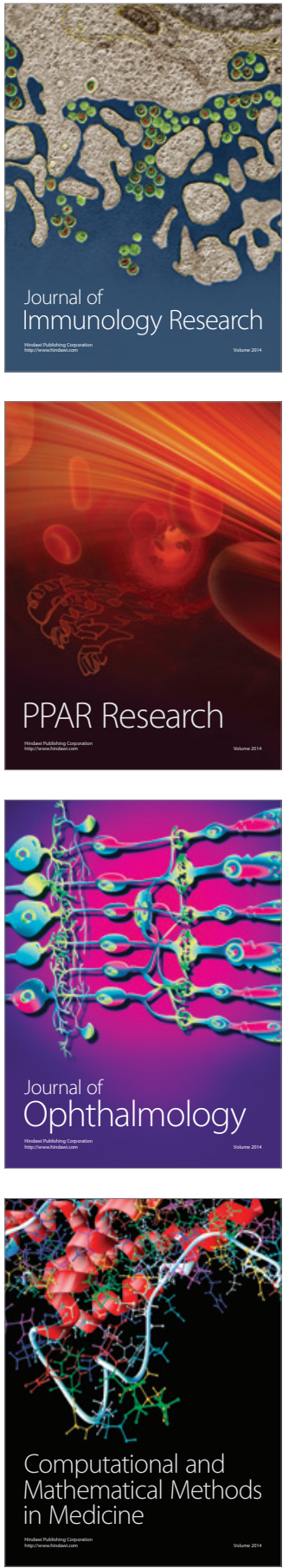

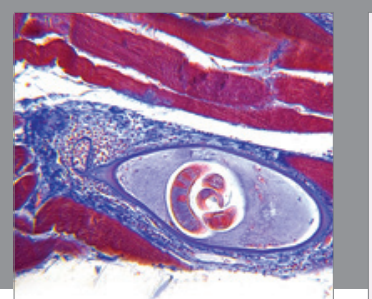

Gastroenterology Research and Practice

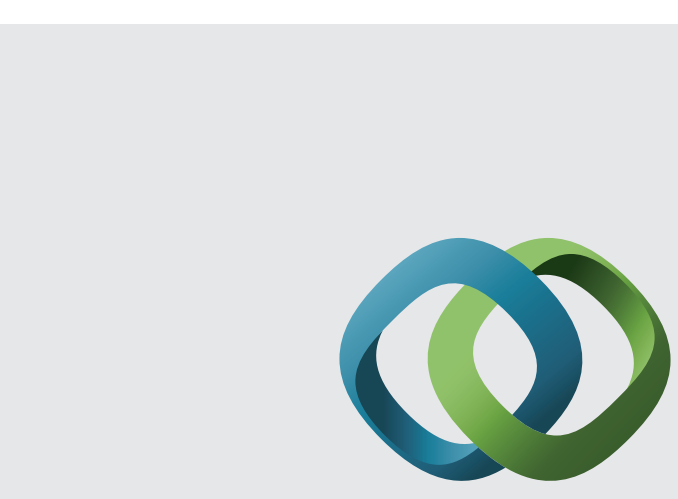

\section{Hindawi}

Submit your manuscripts at

http://www.hindawi.com
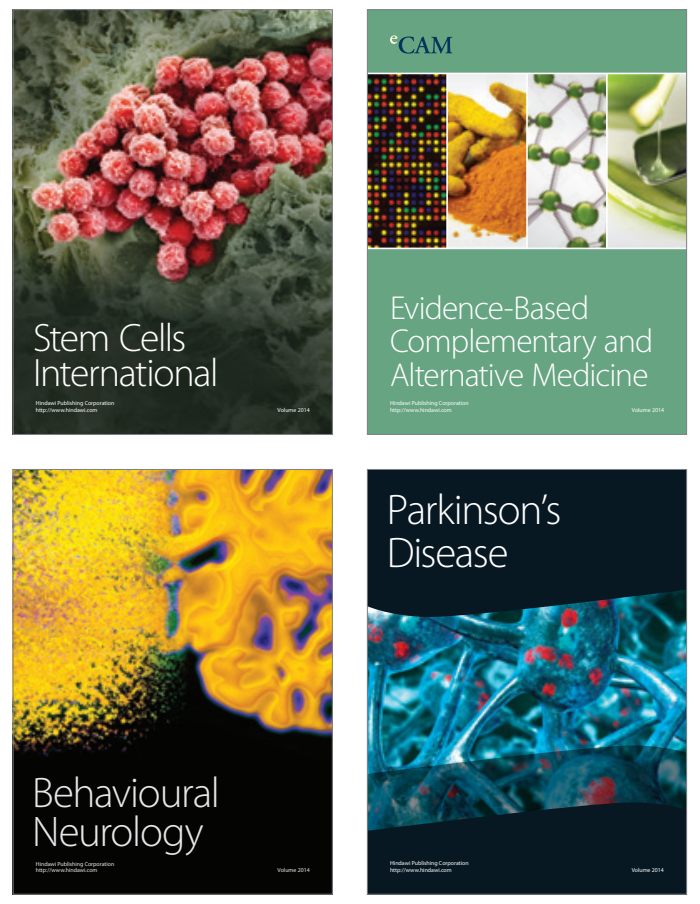
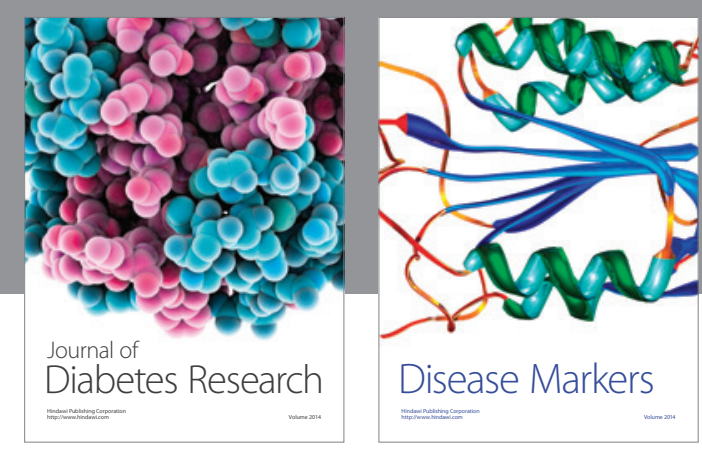

Disease Markers
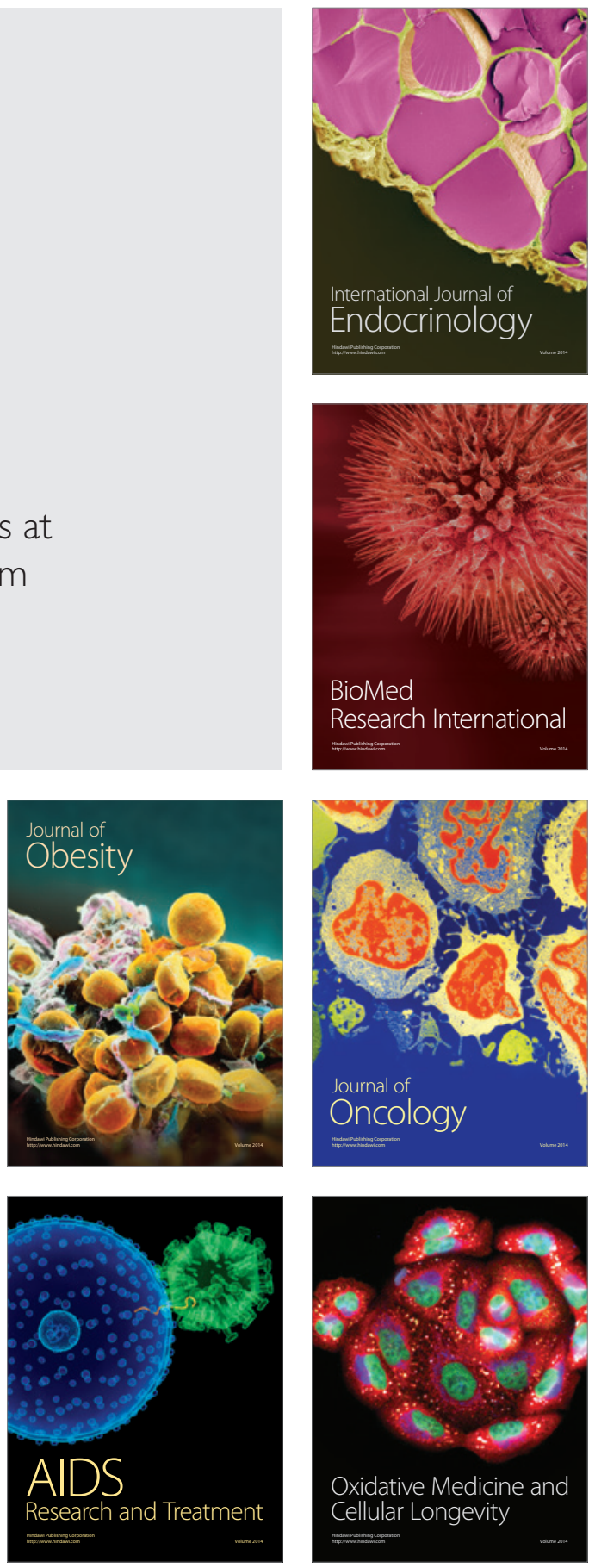